\title{
Transplant Recipients' Experience of Participation at the World Trans- plant Games in Gothenburg 2011: A Study of Psychological Well-being
}

\author{
Urban Johnson $^{1, *}$, Hansi Hinic ${ }^{1}$, Anders Billström ${ }^{2}$ and Håkan Gäbel ${ }^{1}$ \\ ${ }^{1}$ Centre of Research on Welfare, Health and Sport, Halmstad University, Sweden \\ ${ }^{2}$ Centre for Innovation Entrepreneurship and Learning, Halmstad University, Sweden
}

\begin{abstract}
The World Transplant Games (WTG) is a biennial worldwide sporting event. Most published research relating to WTG has focused on medical issues. However, few studies have examined factors such as psychological wellbeing in sport for this group. The purpose of this study is to provide a description of the English-speaking participants at the WTG and analyze five research questions linked to how (1) health, (2), satisfaction with sports participation (3), perceived competence, (4) health as a benefit of sport participation (5), and impaired health as a cost of sports participation, are related to psychological factors in sports. There were a total of 253 participants with a mean age of 43.6 years, originating from seven English-speaking nations. Four validated psychological questionnaires were used, as well as a screening of background data of the group. The main characteristics of the English-speaking population were university educated middle age men with kidney transplants, who had participated in athletics at a rather high competitive level before the transplant. The main statistical findings particularly showed that satisfaction with sport participation, perceived health and health as a benefit were the dependent variables that explained most of the variance in the analysis. In conclusion, perceived competence, enjoyment and health seem to be critical psychological factors that essentially act as prime motivating factors behind participation in games such as WTG, and ultimately lead to a sense of psychological well-being among the participants. Finally, there is a discussion of future research, as well as the practical value of the results.
\end{abstract}

Keywords: Health, participation, psychology, sport, transplant, well-being.

\section{INTRODUCTION}

The World Transplant Games (WTG) is a worldwide biennial sporting event, with the primary aim of raising international awareness of the importance of supporting organ and tissue donation and transplantation and encouraging physical activity and sport participation among transplanted people. In 2011, the sporting event was held in Gothenburg, Sweden where about 1,100 participants from 47 countries took part in 13 events. Moreover, about 700 family members, friends, donors, donor families and the media followed the event on-site. All participants who had undergone an organ or bone marrow transplantation, as well as successfully undergone a thorough examination, by a physician, which included several medical and physical tests, were allowed to compete in the WTG.

Participating in the WTG raises specific medical, physical, psychological and social demands on an athlete, especially those who have a complex history of transplantation, such as a heart-lung transplant. Previous research has clearly pointed out several medical and physical benefits for participation in physical activity aimed at this group, such as physical training resulting in improved endurance, strength and capacity in almost all groups of transplant recipients [1]. Other studies generally state that transplant recipients

*Address correspondence to this author at the Box 823, 30118 Halmstad, Sweden; Tel: +46 (0)-35-167261; Fax: +46 (0)-35-167264;

E-mail: Urban.Johnson@hh.se. tolerate progressive exercise training well and can achieve levels of functioning similar to, or even higher than, those of the general population [2]. Most cited studies have focused on specific demands in relation to medical and physical exercise [3], but few studies have more systematically examined psychological issues such as satisfaction in sport, enjoyment and feelings of perceived competence, in relation to participation in games as the WTG. Increased knowledge of these processes has the potential to enhance our understanding of the needs and expectation of participants, their perception of psychological demands when participating in WTG, and to raise important issues for future organizers of major sporting events including WTG. The results of this study can also contribute to physiotherapists' knowledge of the motivating factors that induce transplant recipients to engage physical activity.

Research focusing on psychological aspects of physical activity for people with transplants shows several positive effects on their general well-being. [1] State that physical training helps the transplanted athletes to heighten their mental readiness for life, and [4] writes about the benefits for the individual to overcome stressors in everyday life. In addition, [2] maintains the advantages of physical activity for increasing the general well-being of individuals. Research directed towards targeted transplant groups also demonstrate advantages of physical training, improved quality of life reported by kidney transplant recipients [5]. Findings indicate that exercise training may improve the functional status of recipients of ventricular assist devices (VAD), even long 
after implantation [6]. Moreover, better quality of life was observed in patients who were physically active after a liver transplant $[7,8]$ clearly compiled several facts concerning physical activity, psychological well-being and WTG saying that "a regaining of physical strength, a return to the ability to compete successfully and for that success to be recognized by the award of a medal is clearly a very positive step. When, as in the World Games, there is the addition of the companionship of peers, the confidence of seeing and meeting hundreds of persons who have triumphed over similar adversity and the embracing warmth of belonging to a worldwide club a truly remarkable benefit becomes obvious to all those present. It is this palpable feeling which gives the Transplant Games their unique flavor" (p. 63). It is also interesting to note that research concludes that for the majority of young people, participating in the WTG were associated with a positive impact on psychological functioning $[9,10]$ similarly states that greater participation in moderate to vigorous physical activities for young people was associated with better psychosocial quality of life.

The research overview clearly indicates several psychological benefits for organ transplant recipients who are active in physical training and sport events such as the WTG. One major result that goes across all presented research is that organ transplant recipients have the potential to achieve levels of health-related well-being similar of those of the general population $[11,12]$ and in some instances, a significant improvement in the recipients' overall quality of life [13]. Thus, the purpose of this study is to analyze and critically discuss the results of data collected by English-speaking participants at the 2011 WTG in Gothenburg, Sweden in relation to psychological well-being factors. More specifically, our aim is to provide a description of the English-speaking participants at the WTG, followed by a study of the succeeding five research questions:

1. How is health related to task and ego motivation orientation, perceived competence and enjoyment in sports?

2. How is satisfaction with sports participation related to task and ego motivation orientation, and health in sports and perceived health?

3. How is perceived competence related to task and ego motivation orientation, perceived competence and enjoyment in sports?
4. How is health as a benefit of sports participation related to task and ego motivation orientation, perceived health, perceived competence and enjoyment in sports?

5. How is impaired health as a cost of sports participation related to task and ego motivation orientation, perceived health, perceived competence and enjoyment in sports?

\section{MATERIAL AND METHODOLOGY}

\section{Participants}

Participants from all English-speaking nations at the 2011 WTG in Gothenburg, Sweden (Australia, England (UK), Ireland, Canada, New Zealand, South Africa and the United States) were asked to answer different psychological questionnaires. A total of 253 participants answered the different questionnaires (see Table 1), divided into 166 men $(63 \%)$ and 87 women $(37 \%)$. The mean age of the sample was 43.6 years $(\mathrm{SD}=16.1)$ with 44.1 years for the men and 43.1 for the women.

\section{Questionnaires}

The questionnaires used in the study consisted of: a) demographic background questions, and, b) four different and well-established psychometric questionnaires.

(1) Demographic data consisting of 12 questions was used. Examples of questions are gender, age, nationality, type of organ transplantation, length of time since most recent transplantation, primary sport, level of competition, present occupation. Both Likert scale and dichotomous answer alternatives were offered.

(2) The Physical Self-Perception Profile (PSPP) [14-16]. The PSPP measures self-perception in five sub-domains: sport competence, strength, condition, body attractiveness and global physical self-worth. In this study, only sports competence was used. The sub-domains are covered by seven statements, to which participants answer how well each describes them, ranging from $1=$ "not true at all" to $4=$ "really true." "I do very well at all kinds of sports" is an example of an item measuring sports competence. The internal consistency for sports competence is 0.79 (Fox, 1990).

Table 1. Summary of English-speaking Participants and Those who Answered the Various Questionnaires at the WTG 2011

\begin{tabular}{|l|c|c|c|}
\hline \multicolumn{1}{|c|}{ Nation: } & Total Number of: Participants: & Questionnaires Answered & Frequency of Answers: \\
\hline \hline Australia & 84 & 45 & $54 \%$ \\
\hline England (UK) & 130 & 74 & $57 \%$ \\
\hline Ireland & 32 & 20 & $63 \%$ \\
\hline Canada & 21 & 18 & $86 \%$ \\
\hline New Zealand & 14 & 14 & $100 \%$ \\
\hline South Africa & 48 & 25 & $52 \%$ \\
\hline USA & 86 & 57 & $66 \%$ \\
\hline \multicolumn{1}{c|}{ Total } & 414 & 253 & $61 \%$ \\
\hline
\end{tabular}


(3) The Perceived Health and Sport Participation (PHSP) [17]. The PHSP measures experience of health and physical activity in terms of costs and benefits. The instrument consists of 30 statements divided into ten categories: health as a goal, health as a means, accumulating health, health as a benefit of sport participation, health as a cost of sports participation, perceived health, satisfaction with sports participation, social influences stimulating healthy sport participation, social influences stimulating unhealthy sports participation, and, impairing health. In this, study perceived health, satisfaction with sport participation, health as a benefit of sports participation, and impaired health as a cost of sports participation were used. The sub-domains are covered by three statements each, to which participants answer how well each describes them, ranging from $1=$ "strongly disagree" to $6=$ "strongly agree". "I am satisfied with my current health" (perceived health), "I am satisfied with my athletic career in general" and (satisfaction with sport participation), are examples of items. The internal consistency (Cronbach's alpha) varied between 0.69 - 0.87 [18].

(4) The Physical Activity Enjoyment Scale (PACES) [19] is an 18 item measurement used to determine how enjoyable an individual finds exercise, and is based on counterpart statements ranging from 1 to 7 . Examples of questions are: "It is not at all stimulating - it is very stimulating" and "It gives me a strong sense of accomplishment it does not give me any sense of accomplishment. Cronbach's alpha is calculated as 0.89 [19].

(5) The Task and Ego Orientation in Sport Questionnaire (TEOSQ) [20]. Participants rate when they feel most successful in sport on a 5-point Likert scale ranging from strongly disagree (1) to strongly agree (5). The statements consist of six statements measuring ego motivation orientation, such as, "I feel the most successful in sport when I am the best", and seven statements measuring task motivation orientation, such as, "I feel the most successful in sport when I learn something new by working hard". The two subscales demonstrate high internal consistency values in this study: Task motivation orientation Cronbach's $\alpha=0.81$ and ego motivation orientation Cronbach's $\alpha=0.80$.

\section{Procedure}

In order to test the validity of the questionnaires and the logistics concerning time for answering the questionnaires, as well as other important issues related to the test situation, a pilot study was conducted during the WTG immediately prior to the Gothenburg games. More specifically, the pilot study was conducted at the WTG 2009 in Brisbane, Australia, based on questionnaires 1-4, which were collected from the English-speaking populations: USA, Australia and England. A more systematic analysis, however, was conducted on the American population $(\mathrm{n}=53)$ and included the addition of a complementary questionnaire (TEOSQ) based on motivational questions [20], since this psychological variable was considered as essential to the understanding of underlying behind participation in competitive settings. Parts of the pilot study have been published by [21]. To increase the response rate and minimize respondent bias the following steps have been important in the data collection process: (a) Regular e-mail communication before the games, and personal meetings with each team managers during the games for the English-speaking countries organized in order to receive permission to collect data during the games by the participants.

(b) To increase the response rate, informed consent forms and questionnaires were distributed in a pre-booked room close to a central assembly point where most of the participants passed by every day to have lunch and dinner during the games.

(c) All researchers were directly involved in assisting participants with answering the various questionnaires onsite.

(d) Directly after the questionnaires were collected, they were transported to Halmstad University and locked in a safe.

The total time for answering the questionnaires varied between 20 and 25 minutes. The research investigation was authorized and approved by an Institutional Ethics Committee for Human Studies. The informed consent forms and a list of participants provided by the local organizing committee and authorized by the World Transplant Games Federation (WTGF) made it possible to identify respondents and non-respondents after the data was collected. To increase the response rate, a reminder consisting of an informed consent form and the questionnaires was sent twice by e-mail to those athletes who did not answer the questionnaire in Gothenburg. This procedure was repeated at an interval of three weeks after the games. The number of respondents increased marginally by a total of seven additional questionnaires.

\section{Statistical Analysis}

Data will be analyzed with descriptive as well as inferential statistics. To investigate predictions, multiple regression analysis with backward elimination will be used. Dependent variables were satisfaction with sport participation, perceived health, health as a benefit of sport participation, impaired health as cost of sport participation (all from the PHSP questionnaire), and perceived competence (PSPP). The reason for using multiple regression analysis is that this allows the assessment of the relationship between one dependent variable and several independent variables [22].

\section{RESULTS}

The results section is divided into two parts. Descriptive data will be presented initially, followed by multiple regression analysis in relation to the stated purposes of the study.

\section{Descriptive Data based on the English-Speaking Popula- tion}

The most common transplant organs were kidneys $(50 \%)$, followed by liver $(22 \%)$ and heart (12\%), evenly distributed among men and women (see Table 2). The average length of time since the participants received their last transplants was 9.91 years ago (SD 7.25). The sports with the highest participation rates were: athletics (27\%), swimming $(15 \%)$, golf $(10 \%)$ and cycling $(10 \%)$ (See Table 3). Previous sport experience before the transplantation was divided 
Table 2. Demographic data for English-speaking participants at the WTG 2011, (N=253)

\begin{tabular}{|l|c|c|c|c|}
\hline \multicolumn{1}{|c|}{ Transplanted Organs } & Frequency & Percent & Male & Female \\
\hline \hline Kidney & 126 & 49.7 & 22 & 40 \\
\hline Liver & 56 & 11.9 & 24 & 6 \\
\hline Heart & 30 & 5.2 & 8 & 5 \\
\hline Cell transplant & 13 & 5.2 & 6 & 6 \\
\hline Lung & 13 & 2.8 & 5 & 2 \\
\hline Heart/Lung & 7 & 1.4 & 1 & 3 \\
\hline Liver/kidney & 4 & 1 & 2 & 0 \\
\hline Pancreas & 3 & & \\
\hline
\end{tabular}

Table 3. Five Most Frequent Answers Concerning Primary Sport Among Participant at WTG 2011 (n=248)

\begin{tabular}{|c|c|c|}
\hline Five Primary Sports & Frequency & Percent \\
\hline \hline Athletics & 69 & 26.6 \\
\hline Swimming & 39 & 15.4 \\
\hline Golf & 26 & 10.5 \\
\hline Cycling & 25 & 10.1 \\
\hline Bowling & 24 & 8.7 \\
\hline
\end{tabular}

into the following: elite sport (11\%), sub-elite sport (14\%), competitive level (24\%), recreational level (32\%) and none $19 \%$. In terms of educational level, $47 \%$ reported having an undergraduate university degree, while $32 \%$ reported high school or equivalent and $16 \%$ university at a graduate level. Concerning occupations, $63 \%$ reported white collar, $12 \%$ blue collar and $21 \%$ others (see Figs 1-3).

\section{Multiple Regression based on the English-Speaking Population}

Concerning the first stated research question, multiple regression analysis showed a significant relation between perceived health and predictors (task and ego motivation orientation, enjoyment and perceived competence), $\mathrm{f}(4249)=$

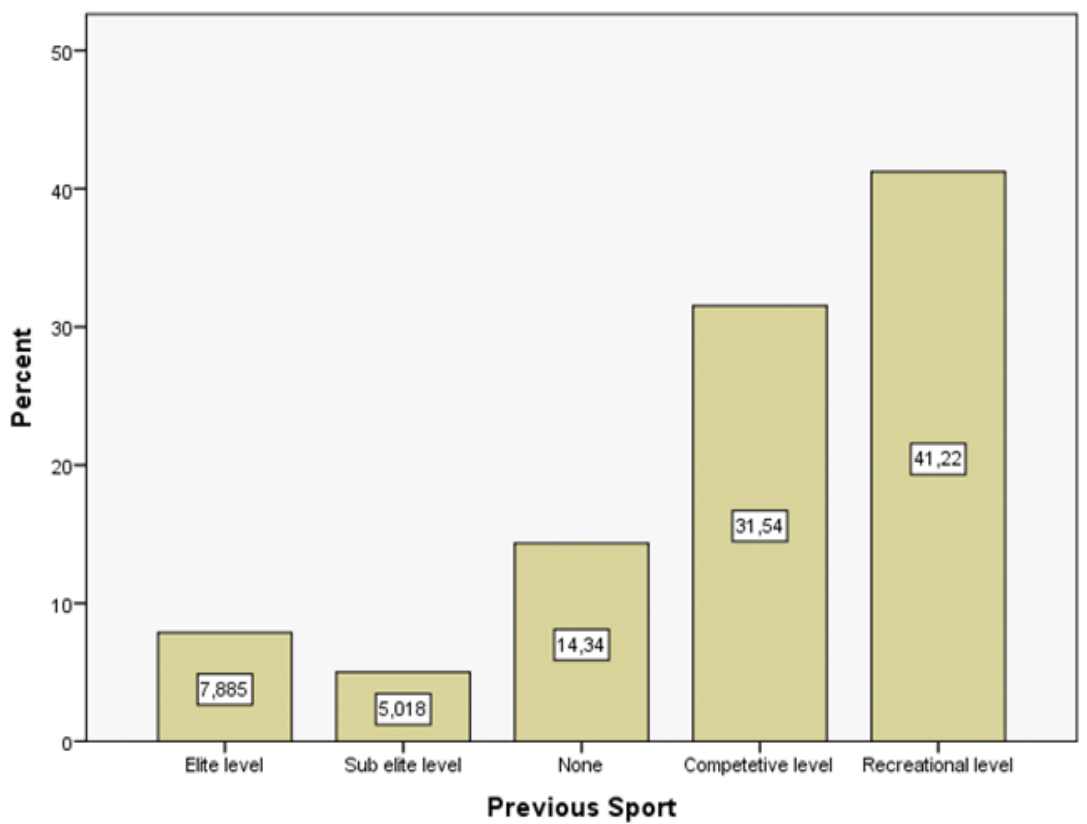

Fig. (1). The figure shows participants previous sport participation prior transplantation $(n=249)$. 


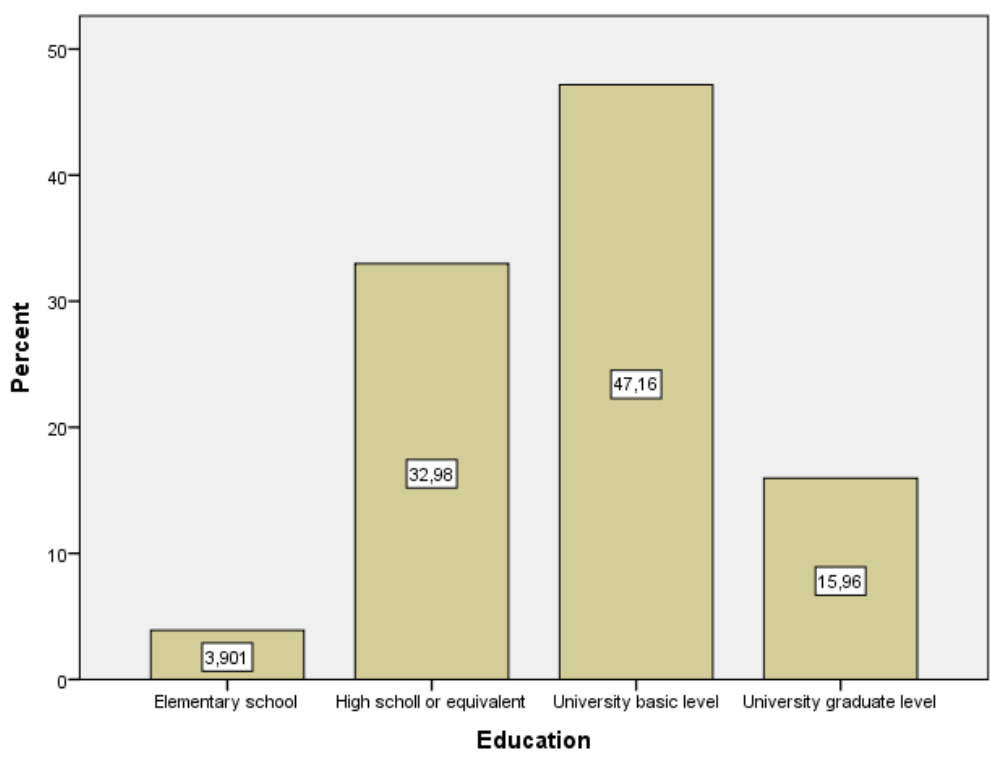

Fig. (2). The figure shows participants education level $(n=242)$.

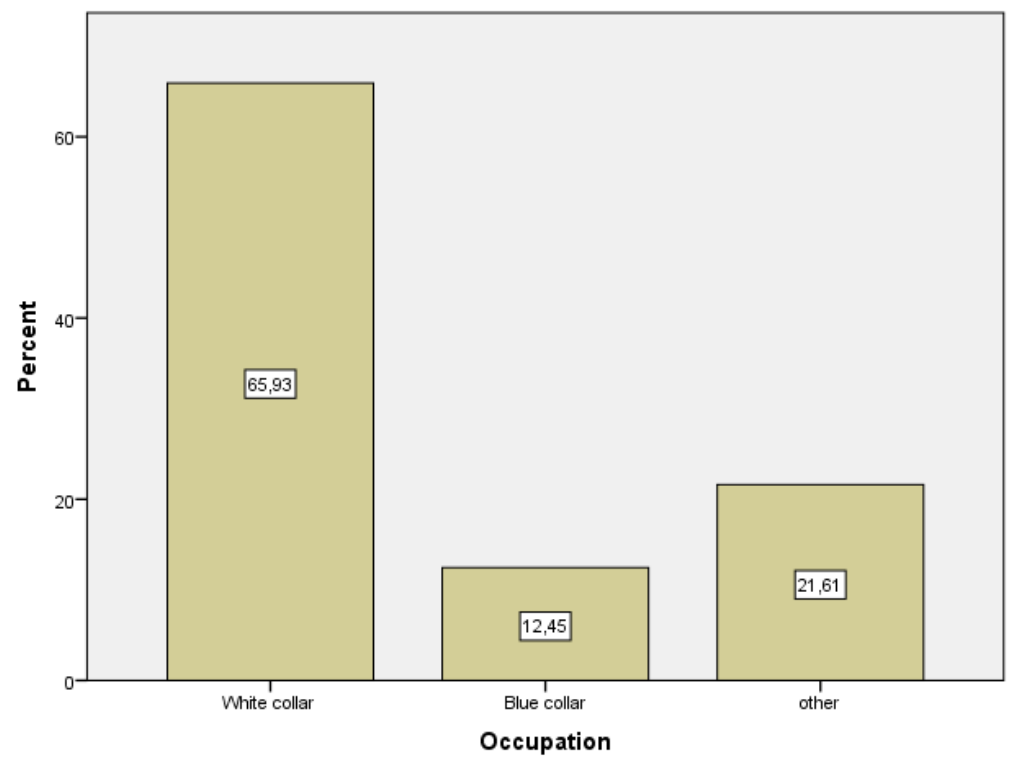

Fig. (3). The figure shows participants occupation level $(n=243)$.

$10.03, p<.001$. Significant predictors were perceived competence and enjoyment. The model explained $27 \%$ of the total variance. As to the second stated research question, multiple regression analysis showed a significant relation between satisfaction with sport participation and predictors (task and ego motivation orientation, perceived competence and health), $f(4249)=40.97, p<.001$. Significant predictors were perceived competence and perceived health. The model explained $36 \%$ of the total variance. In the case of the third stated research question, multiple regression analysis showed significant relation between perceived competence and predictors (task and ego motivation orientation, enjoyment and health), $\mathrm{f}(4,249)=15.91, \mathrm{p}<.001$. Significant predictors were negatively related to ego, and positively related to enjoyment. The model explained $18 \%$ of the total variance. According to the fourth stated research question, multiple regression analysis showed a significant relation between health as a benefit of sport participation and predictors (task and ego motivation orientation, perceived competence, enjoyment and perceived health), $f(5,248)=21.78, \mathrm{p}<.001$. Significant predictors were perceived competence, enjoyment and perceived health. The model explained $27 \%$ of the total variance. Finally, in the case of the fifth stated research question, multiple regression analysis showed significant relation between impaired health as a cost and predictors (task and ego motivation orientation, enjoyment, perceived competence and health $), f(5,249)=6.40, p<.001$. Significant predictors were enjoyment and perceived health, both negatively related. The model explained $10 \%$ of the total variance (see Table 4). 
Table 4. Table Shows Relation between Dependent Variables and Psychological Factors. Unstandardized Beta and $\mathbf{R}^{2}$ Adjusted Values are Shown $(n=253)$

DEPENDENT VARIABLES

\begin{tabular}{|c|c|c|c|c|c|}
\hline Psych. Factors & $\begin{array}{c}\text { Perceived Health } \\
R^{2} \text { adj. }=.272\end{array}$ & $\begin{array}{c}\text { Satisfaction in Sport } \\
\mathbf{R}^{2} \text { adj. }=.365\end{array}$ & $\begin{array}{c}\text { Perceived Competence } \\
\mathbf{R}^{2} \text { adj. }=.177\end{array}$ & $\begin{array}{c}\text { Health as a Benefit } \\
\quad \mathbf{R}^{2} \text { adj. }=.272\end{array}$ & $\begin{array}{c}\text { Impaired Health } \\
\text { as a Cost } \\
\mathbf{R}^{2} \text { adj. }=.10\end{array}$ \\
\hline Perceived competence & .165 & .317 & & .115 & \\
\hline Enjoyment & .279 & & .256 & .172 & -.181 \\
\hline Perceived health & & .459 & & 380 & -.216 \\
\hline Ego motivation orientation & & & -.253 & & \\
\hline
\end{tabular}

\section{DISCUSSION}

The purpose of the study was to provide a description of the English-speaking participants at the 2011 WTG in Gothenburg, Sweden, as well as answering five research questions linked to how (1) health, (2) satisfaction with sports participation, (3) perceived competence, (4) health as a benefit of sport participation, and (5) impaired health as a cost of sport participation were related to a selection of psychological factors in sports. A brief description of the main features of the English-speaking population at the games is that about $2 / 3$ were men, with a total mean age of 44 years. The most common transplant organs were kidneys (50\%), and about 10 years $(\mathrm{SD}=7.1$ years $)$ had passed since receiving last transplant. The most common sport participated in was athletics $(27 \%)$, and about the half of the population had previous sport experience before the transplantation on a competitive to elite level. A majority of the athletes had a university educational level, and about $2 / 3$ reported white collar as their occupational status. The main findings from the multiple regression analyses showed particularly that satisfaction with sport participation, perceived health and health as a benefit were the dependent variables that were mostly explained by a variety of predictors such as enjoyment in sport. The following section will discuss the results, view methodological considerations, and then discuss practical value of the results.

\section{Analysis of the Descriptive and Inferential Results}

About 15 years have passed since the latest (and only) research study was published describing levels of health related fitness and quality of life of English-speaking organ transplant recipients at a major sport event for transplant recipients [12]. In this study, some 128 transplant recipients from the American team were asked to answer questionnaires foremost associated to health-related quality of life. It is interesting to note the similarities in the two populations (English-speaking participants vs. American participants) in terms of the mean age of the sample ( 44 vs. 43 years), gender distribution (63/37\% vs. about 69/41\%), mean time since last transplantation (10 vs. 10 years) and highest level of education (both undergraduate university). Basically, this tells us that the demographics of the English-speaking population studied here share many of the same features as the group in the study several years ago [12]. Some other strik- ing results from the demographics is the relatively high level of sports participation the respondents had before transplantation (about 50\% engaged in competitive sport), with about $1 / 4$ reporting elite/sub elite as their previous sport level. In light of this previously high competitively-oriented physical activity of many of the participants, which may indicate that medals and achieving excellent results were highly valued, it is interesting to observe that satisfaction with sport participation and perceived health were now the main characteristics of participants involved in the games, according to multiple regression analysis. Given the quotation in the introduction [4], which, in essence, states that it is the comradeship of peers, the return to being physically active again and the triumph of coping with adversities in life that give the games their unique flavor, it is no surprise that the apparently reappraised attitude towards the competitive aspects of the games are diminished and partly replaced by other basic needs for participation, such as social and wellbeing factors. This notion is also stressed by $[1,5]$, who emphasize several advantages of physical training for transplanted athletes, such as improved quality of life rather than mere competition. It is also interesting to note the relatively high educational level of participants at the WTG (62\% university degree) as compared to statistics from other Western countries in relation to educational background and sport participation. For instance, [23] report considerably lower levels of those holding university degrees among sport participants across different team and individual sports in Europe. It is most likely fair to conclude regarding this issue that, in general, many of the English-speaking participants at the games seem to have a stable socioeconomic status, which enables them to finance the rather costly participation in the games. This conclusion is also buttressed by the fact that a majority of the participants stated their occupational level as "white collar" probably due to a rather high educational background and presumably, an average/high annual income.

Returning to the results of the multiple regression analysis, participation in the game is undoubtedly associated with satisfaction derived from sports participation, a perceived feeling of health, and a view that participation brings positive benefits in the form of improved health. While these results are not exclusive to transplant recipients involved in sport, massive evidence show several positive psychological effects of physical activity [14], such as enhanced self- 
esteem, improved mood states, reduced state and trait anxiety, resilience to stress, and improved sleep, it is especially important to mention the high $\mathrm{R}^{2}$ adjusted values for satisfaction in sport $\left(\mathrm{R}^{2}\right.$ adj.=.365) significantly predicted by perceived competence and health. This result most likely demonstrates the important nature of the games as emphasizing inclusion and participation for all, as well as being games that instill self-confidence and promote a healthy lifestyle among many of the participants. Moreover, the results are easily translated to the concept of quality of life, which in many studies is associated with organ transplantation and improvement in the recipients overall psychological wellbeing [13] . In addition the results indicate that transplant recipients can return to a normal life, and, despite some additional risks, can participate in sporting activity, and exercise with considerable safety [11]. The results also revealed that impaired health as a cost of participation was negatively associated with both enjoyment and perceived health. This result is no surprise and just underscores the importance of seeing the events (sports) as highly satisfying and having a clearly healthy outcome as a result.

Another result that justifies a comment is the rather high Standard Deviation of the mean age $(\mathrm{SD}=16.1)$ of the participants as well as the Standard Deviation for years since transplant $(\mathrm{SD}=7.1)$. Some of the participants were rather young transplant athletes, and as [9] also state, the games seem to bring several psychological benefits to this group, especially in the form of high perceived competence and enjoyment in sports. This group of young athletes probably receives positive confirmation of their physical ability that may well lead to a life-long investment in healthy lifestyles such as being physically active despite a potential serious history of transplantation.

Even though the results of the present study do not allow an analysis of caregivers, it is noteworthy that results from other studies, for instance [24], show that the most commonly reported benefit of being a caregiver was helping the patient, and that the most common stressors were associated with uncertainty, waiting and worry. It is possible that the high overall levels of psychological well-being and satisfaction among participants are also reflected positively among caregivers. However, this hypothesis has to be confirmed by future research. To be involved in physical activity and participate in events such as the WTG may reduce, at least temporarily during the games, the stressors found by [24]). From a societal perspective, the games may be important to not only increase the awareness of organ and tissue donation, but also to encourage people to get involved in physical activity to reduce the chance of impaired health.

\section{Methodological Considerations}

The main reason for studying the five selected dependent variables, and thus potentially narrowing the scope of the study, was that these psychological variables have been singled out as significant in previous studies. The inclusion of only the English-speaking population limits, of course, the generalization of the results. Due to the nature of the questionnaires (validated on an English population and this time/costly to translate) analyses of all English-speaking nations participated. Therefore the results are generalized within this restriction. Choosing another statistical method of analyzing the result could potentially bring more elaborated results to be discussed (e.g. logistic regression). However, the decision to use multiple regression was based on a desire to facilitate the interpretation make the results easy to understand. The population generally has a rather high educational level, a fact that needs to be considered when comparing the results outside the transplant context.

\section{Practical Value of the Results}

The results of the study suggest some tips and proposals for future managers of the WTG. It is important to facilitate an open atmosphere and continue to stimulate comradeship and healthy habits. Moreover it is also essential to emphasize health as a leading benefit of sports participation and not increase the competitive pressure on participants (even though a competitive approach to the games/events should be allowed). This fact is particularly noted in relation to high value of health as a benefit and satisfaction in sports. It is also vital to recognize and continue to stimulate individual satisfaction with physical activity, as well as feelings of perceived competence, regardless of the competitive results of the games, demonstrated in high perceived competence and perceived health. Future organizers must realize the importance of encouraging other types of people, such as young adults with less competitive experience in sports, in order to increase the physical activity among transplant recipients. From a societal perspective, it is especially important to encourage children and adolescents to get involved in physical activity because people with previous sport experience seem to be a majority at the games. In addition, it is also important to encourage transplant recipients to participate in sports to increase the likelihood of the kind of psychologically and physiologically healthy life to which the WTG may contribute.

\section{CONCLUSIONS}

The overall conclusion of the study is that perceived competence, enjoyment and health seem to be critical psychological factors that essentially act as prime motivating factors for participation in games such as WTG, and ultimately lead to a sense of psychological well-being among the participants. Several interesting and future research questions emerge from the data. Two particularly promising research projects involve (a) conducting a psychological analysis of care givers at the game, and (b) a targeted study of separate age cohorts (e.g. younger and older athletes) in order to learn more about which psychological needs each groups has.

\section{CONFLICT OF INTEREST}

The authors confirm that this article content has no conflicts of interest.

\section{ACKNOWLEDGEMENTS}


We acknowledge financial help from Centre for Sport Science, Sweden (P2012-0127) making this study possible. We also want to thank MSc Arne Edvardsson for help collecting the data. Finally we also want to thank the local organizing committees, World Transplant Games Federation and team managers who allowed us to collect data and get in contact with the athletes.

\section{REFERENCES}

[1] Kjear M, Beyer N, Secher NH. Exercise and organ transplantation. Scand J Med Sci Sports 1999; 9: 1-14.

[2] Painter M. Physical functioning in end-stage renal disease patients. Hemodial Int 2005; 9:218-35.

[3] Tomczak CR, Warburton DE, Ries, KJ, et al. Pulmonary oxygen uptake and heart rate kinetics during the six-minute test in transplant recipients. Transplantation 2008; 85: 29-35.

[4] Slapak M. Sport and transplantation. Ann Transplant 2005a; 10: 60-7.

[5] Krasnoff JB. Liver disease, transplant, and exercise. Clin Exerc Physiol 2001; 3: 27-34

[6] Laoutaris ID, Dritsas A, Adamopoulos S, et al. Benefits of physical training on exercise capacity, inspiratory muscle function, and quality of life in patients with ventricular assist devices long-term post implantation. Eur J Prev Cardiol 2011; 18: 33-40.

[7] Rongies W, Stepniewska S, Lewandowska M, et al. Physical activity long-term after liver transplantation yields better quality of life. Ann Transplant 2011; 16: 126-31.

[8] Slapak M Sport for the transplant athlete - Just harmless fun or a valuable tool? Ann Transplant 2005b; 10: 24-8.

[9] Wray, Lennon-Wood T. Psychological benefits for children and adolescents who have undergone transplantation of the hearth from participation in the British Transplant Games. Cardiol Young 2008; 18: $185-8$.

[10] Ikeda Y. The influence of physical activity on the psychological well being of children who have undergone a liver transplant. Dissertation, Sci Eng 2008; 68: 7248.
[11] Griffin P. Exercise and sport after organ transplantation. Br J Sports Med 1998; 32: 194

[12] Painter PL, Luetkemeir MJ, Moore GE, et al. Health related fitness and quality of life in organ transplant recipients. Transplantation 1997; 64: 1795-800.

[13] Burra P, De Bona M, Germani G, et al. The concept of quality of life in organ transplantations. Transplant Proc 2007; 39: 2285-7.

[14] Fox KR. The influence of physical activity on mental wellbeing. Public Health Nutr 1999; 2: 411-8.

[15] Fox KR, Corbin CB. The physical self-perception profile, development and preliminary validation., J Sport Exerc Psychol 1989; 11: 408-30.

[16] Fox KR. The physical self perception profile manual. Dehab, IL: Office for Health Promotion, Northern Illinois University 1990.

[17] Stambulova N, Johnson U, Lindwall M, et al. Upplevd hälsa ur ett motions/träningsperspektiv: Avslutande studie av arbetsmodellen och validering av instrumentet. Stockholm: Centrum för Idrottsforskning 2006.

[18] Gestranius J. Factors influencing exercisers' tendencies towards healthy versus unhealthy exercise participation. Sweden: School of Social and Health Sciences: Halmstad University; 2008.

[19] Kendzierski D, Decarlo KJ. Physical activity enjoyment scale: Two validation studies. J Sport Exerc Psychol 1991; 13: 62-3.

[20] Duda JL, Whitehead J. Measurement of goal perspective in the physical domain. In: Duda JL, Whitehead J, Eds. Advances in sport and exercise psychology measurement. Morgantown, WV: Fitness Information Technology 1998; pp. 21-48.

[21] Gäbel $H$. Investigation of physical benefits of comprehensive sports for transplant recipients. Transworld, 2010; 1 .

[22] Tabachnick BG, Fidell LS. Using Multivariate Statistics. $6^{\text {th }}$ ed. Boston : Allyn and Bacon. 2012.

[23] Van Tuyckom C, Scheerder J. Sport for all? Insight into stratification and compensation mechanisms of sport activity in the 27 European Union member states. Sport Educ Soc 2010; 15: 495513.

[24] Meltzer LJ, Rodrigue JR. Psychological distress in caregivers of liver and lung transplant candidates. J Clin Psychol Med Settings 2001; 8: 173-80 